\title{
Selective Androgen Receptor Modulator RAD140
}

National Cancer Institute

\section{Source}

National Cancer Institute. Selective Androgen Receptor Modulator RAD140. NCI

Thesaurus. Code C137950.

An orally bioavailable, non-steroidal selective androgen receptor modulator (SARM), with potential tissue-selective androg enic/anti-androg enic activities. Upon oral administration, SARM RAD140 acts as an agonist in select tissues, such as skeletal muscle and bone, where it binds to and activates androgen receptors (ARs). In the prostate and breasts, RAD140 acts as an antagonist and blocks AR activation and AR-mediated cellular proliferation. Therefore, this agent may improve bone formation and muscle mass and strength, and may inhibit both the growth of the prostate in males and AR-dependent breast cancer cell proliferation. Compared to anabolic agents, SARMs have reduced androgenic properties. 